井上正美，榎本三郎

富山大学 薬学部1)

\title{
Methylation of Phenols using Metal-Salt Catalysts
}

\author{
Masami Inoue and Saburo Enomoto \\ Faculty of Pharmacentica! Sciences, Toyama University')
}

(Received February 5, 1976)

\begin{abstract}
Methylation of phenols by methanol was examined with metal salts. At $350^{\circ}$, anisole was formed selectively from phenol and methanol in the presence of chlorides, sulfides, and phosphates of iron and chromium. With $1 \mathrm{~g}$ of chromic phosphate $\left(\mathrm{CrPO}_{4} \cdot 1.8 \mathrm{H}_{2} \mathrm{O}\right)$, conversion reached $45 \%$ and the selectivity to anisole was $95 \%$ at $375^{\circ}$ for $12 \mathrm{hr}$ from phenol $(10 \mathrm{~g})$ and methanol $(15 \mathrm{~g})$. In contrast, aromatic carbon atoms of phenols were methylated by methanol in the presence of metal nitrates. Especially, ferric nitrate and chromium nitrate showed better activity to ortho-methylation.

The selectivity of anisole formation and ortho-methylation was discussed in terms of different characters of metal salts.
\end{abstract}

フェノール類のメチルェーテル体は強アルカリ性の下でジメチル硫酸を作用させることにより高収率, 選択的 に行なわれている。しかし、ジメチル硫酸の毒性が高いこと, 廃液中に未反応原料捛よび副生硫酸ナトリウムが 高濃度に含变れてくるので後処理がはん雑である，そこで，理想的反店系としてフェノールとメタノールの触媒 反㐫がもとめられている。メタノールをアルキル化剂として触媒の存在下，フェノール類のエーテル化を行なっ た例として，フェノールとメタノールから BF 3 を触媒とし，170 でアニソールが得られていることを挙げるこ とができる.2) 著者らは，さらに取り扱いの容易な触媒系を探索し，金属塩の5ち Fe 技よび Crのリン酸塩が $300-375^{\circ}$ でフェノール類のエーテル化を選択的に行な5ことを見い出した。一方，硝酸塩を触媒とすれば ortho 位核メチル体が得られた，そこで，アルキル化に対する金属塩の特性を反応条件に対する生成物の分布， 変換率の相違等から明らかにすることを目的とした。

\section{実 験 の 部}

反応方法ならびに生成物の分析 容量 $100 \mathrm{ml}$ の誘導回転式オートクレーブ（新坂下製作所製 SR 型）を用 い,フェノール類 $10 \mathrm{~g}$, メノール $15 \mathrm{~g}$, 金属塩 $1 \mathrm{~g}$ を仕込み, 水素堪換したのち $800 \mathrm{rpm}$, 所定温度でメチ

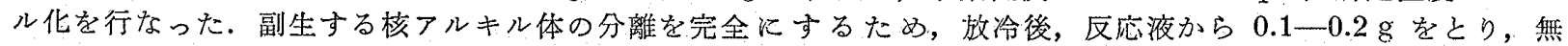
水酢酸ーピリジン $(10: 1)$ 混合液 $3 \mathrm{ml}$ でアセチル化 $\left(90^{\circ}, 30 \mathrm{~min}\right)$ したのち, $20 \%$ tricresyl phosphate+diisodecyl phthalate (7:3)-Chamelite CK (80-100 mesh) (キシダ化学製) $3 \mathrm{~mm} \phi .2 \mathrm{~m}$ を用い，ガスクロマト グラフ（日立製作所製 063 型）によって原料ならびに生成物を分離定量した。

\section{結 果と考察}

\section{金属塩を触媒とするフェノール類のメチル化}

画性拉よび酸性酸化物の存在下, $350-440^{\circ}$ でフェノールとメタノールからアニソールが生成することはすで に知られているがメチル基の転位による核メチル体が生成するため，ニーテル体への選択性が低い.3）一方，金属 塩の中にはエーテル化を選択的に行らものがあることを見い出した. $\mathrm{Mg}, \mathrm{Mn}, \mathrm{Fe}, \mathrm{Cr}$ がこの例で，これらのう ち $\mathrm{Mg}, \mathrm{Mn}, \mathrm{Fe}$ に比較して $\mathrm{Cr}$ が最も高い活性を示した. $\mathrm{Zn}, \mathrm{Al}$ の程はメチル基の転位と異性化を伴うので選

1) Location: 3190, Gofuku, Toyama.

2) F.J. Sowa, G.F. Hennion, J.A. Niewland, J. Am. Chem. Soc., 57, 709 (1935).

3) M. Inoue, S. Enomoto, Chem. Pharm. Bull. (Tokyo), "in press". 
TABLE I. Methylation of $p$-Cresol by Methanol in the Presence of Metal Salts at $350^{\circ}$

\begin{tabular}{lccc}
\hline \multicolumn{1}{c}{ Catalyst } & $\begin{array}{c}p \text {-Cre } \\
(\mathrm{mol} \%)\end{array}$ & $\begin{array}{c}p \text {-Me- } \\
\text { Anis. } \\
(\text { mol \% })\end{array}$ & $\begin{array}{c}2,4-\mathrm{Xyl} . \\
(\mathrm{mol} \%)\end{array}$ \\
\hline $\mathrm{FeCl}_{3} \cdot 6 \mathrm{H}_{2} \mathrm{O}$ & 93.1 & 4.3 & 2.6 \\
$\mathrm{CrCl}_{3} \cdot 6 \mathrm{H}_{2} \mathrm{O}$ & 90.9 & 5.3 & 3.8 \\
$\mathrm{FePO}_{4} \cdot 4 \mathrm{H}_{2} \mathrm{O}$ & 97.2 & 2.8 & 0 \\
$\mathrm{CrPO}_{4} \cdot 1.8 \mathrm{H}_{2} \mathrm{O}$ & 70.6 & 29.4 & trace \\
$\mathrm{Fe}_{2}\left(\mathrm{SO}_{4}\right)_{3} \cdot 5.7 \mathrm{H}_{2} \mathrm{O}$ & 74.0 & 26.0 & trace \\
$\mathrm{Cr}_{2}\left(\mathrm{SO}_{4}\right)_{3} \cdot 2.9 \mathrm{H}_{2} \mathrm{O}$ & 68.0 & 28.2 & 3.8 \\
\hline
\end{tabular}

p-cresol $10 \mathrm{~g}, \mathrm{MeOH} 15 \mathrm{~g}$, catalyst $1 \mathrm{~g} .250^{\circ}, 4 \mathrm{hr}\left(\mathrm{H}_{2}\right)$

TABle II. Methylation of $o$-Cresol by Methanol in the Presence of Metal Nitrates at $400^{\circ}$

\begin{tabular}{|c|c|c|c|c|c|c|c|c|}
\hline \multirow{2}{*}{ Catalyst } & \multirow{2}{*}{$\begin{array}{c}\mathrm{R} . \\
\text { time } \\
(\mathrm{hr})\end{array}$} & \multirow[b]{2}{*}{ o-Cre. } & \multicolumn{5}{|c|}{ Products (mol \%) } & \multirow[b]{2}{*}{$\mathrm{PhOH}$} \\
\hline & & & 2,6-Xyl. & $2,4-\mathrm{Xyl}$ & $\begin{array}{l}2,4,6- \\
\operatorname{TMP}^{a)}\end{array}$ & $\mathrm{o}-\mathrm{MA}^{b)}$ & $\begin{array}{c}2,6- \\
\text { DMA }^{(c)}\end{array}$ & \\
\hline $\mathrm{Ce}\left(\mathrm{NO}_{3}\right)_{3} \cdot 6 \mathrm{H}_{2} \mathrm{O}$ & 3 & 28.9 & 43.3 & 25.3 & 1.2 & 1.3 & trace & trace \\
\hline $\mathrm{Al}\left(\mathrm{NO}_{3}\right)_{3} \cdot 9 \mathrm{H}_{2} \mathrm{O}$ & 3 & 52.3 & 33.0 & 10.2 & 0 & 4.5 & 0 & 0 \\
\hline $\mathrm{Fe}\left(\mathrm{NO}_{3}\right)_{3} \cdot 9 \mathrm{H}_{2} \mathrm{O}$ & 3 & 51.7 & 42.5 & 3.5 & 1.5 & 0.8 & 0 & 0 \\
\hline $\mathrm{Be}\left(\mathrm{NO}_{3}\right)_{3} \cdot 3 \mathrm{H}_{2} \mathrm{O}$ & 3 & 55.7 & 34.1 & 6.8 & 2.3 & 1.1 & 0 & 0 \\
\hline $\mathrm{Th}\left(\mathrm{NO}_{3}\right)_{4} \cdot 4 \mathrm{H}_{2} \mathrm{O}$ & 1 & 30.1 & 59.0 & trace & 9.6 & 1.3 & trace & 0 \\
\hline $\mathrm{Cr}\left(\mathrm{NO}_{3}\right)_{3} \cdot 9 \mathrm{H}_{2} \mathrm{O}$ & 3 & 47.7 & 45.4 & trace & 4.7 & 1.4 & 0.8 & 0 \\
\hline
\end{tabular}

catalyst $1 \mathrm{~g} ; \mathrm{o}$-cresol $10 \mathrm{~g}$; methanol $15 \mathrm{~g}$; atmosphere air;

a) trimethyl phenol $b$ ) methyl anisole $c$ ) dimethyl anisole

択性の点から適当でない. Table I 飞種々の $\mathrm{Fe}, \mathrm{Cr}$ の塩を用いてpーグレ゙ールのメチル化を行った結果を示 す. 塩酸塩はいずれも活性が低い。フリーデルクラフッ型の無水塩化鉄を用いても変換率の大幅な上昇が認めら れず，幾分転位を起すので少量の水の存在は選択性を高めるのに有効であると考兄られる，また，反応が進行す れば水の生成が避けられないので, Brónsted 型の酸触媒反応と考兄られる. 硫酸塩では生成物中に黒褐色物質 を副生し，触媒自身の分解子認められるので本反応には好をしくない．

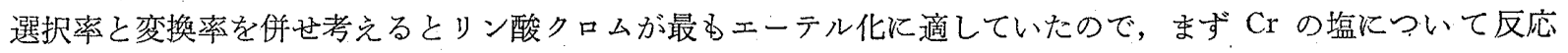
条件をしらべた。また，一般に，金属の程酸塩，硫酸塩，リン酸塩がエーテル体を生成するのとは対照的に硝酸 塩では核メチル体を生成し，特に，硝酸鉄，硝酸クロムはフェノール類の ortho 位核メチル化に選択性を示した. これを Table.II に示す.

\section{リン酸クロムによるフェノールのメチル化}

フェノールのメチル化漈して変換率と選択性に招よ涪す反応温度の影響を Fig. 1 に示す.

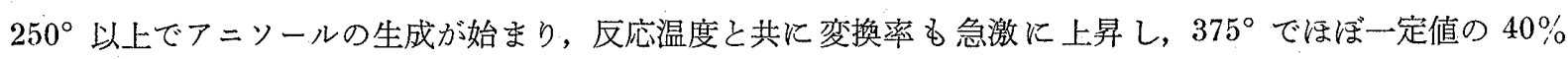

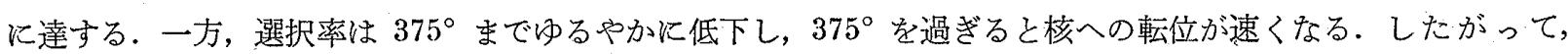
反応温度は $375^{\circ}$ を限とした． $350^{\circ}, 375^{\circ}$ の 2 点を選えでメチル化を行った結果を Fig. 2、に示す. $350^{\circ}, 7$ $\mathrm{hr}$ では変換率 $30 \%, 375^{\circ}, 12 \mathrm{hr}$ では $45 \%$ 洼達する。

系代対する触媒濃度を $2 \%$ から $12 \%$ まで增加させると変換率は $350^{\circ} ， 5 \mathrm{hr}$ の反応で触媒添加量 $4 \%$ まで 上昇し, これ以上でほ泀汪一定值の $35 \%$ となる。このことは, 経時変化に扣ける結果と同様, フェノール, メタ ノール，アニソール間に平衡が成立していることを示している．アルキル化棛としてのメタノールに変光てェタ ノール，プロピルアルコールを用いるとアルキルフェニルエーテルの転位招よび脱アルキル化が激しく選択性が 低下した. このこともまた酸触媒反応によるアルキル化の特徵を示している。 


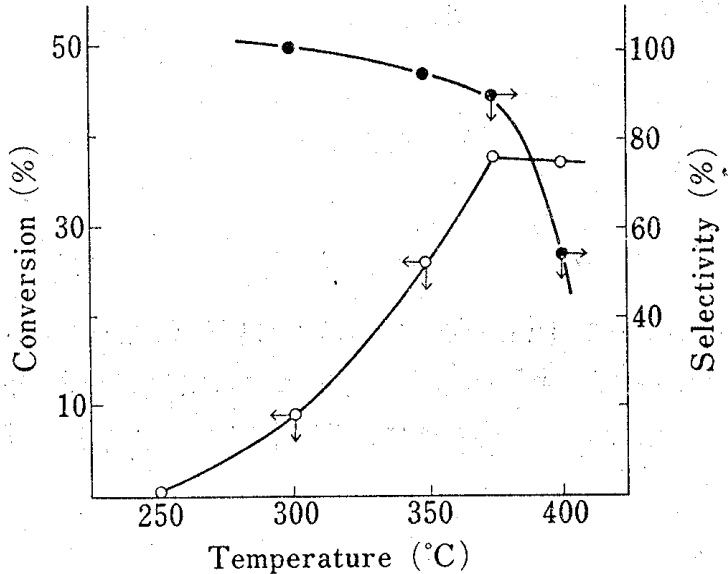

Fig. 1. Temperature Dependence of Conversion and Selectivity in the Methylation of Phenol with Chromic Phosphate.

Phenol $(10 \mathrm{~g})$, methanol $(15 \mathrm{~g})$ and chromic phosphate $(1 \mathrm{~g})$ were used.

The methylation was performed for $5 \mathrm{hr}$.

-O-: conversion

: selectivity to anisole

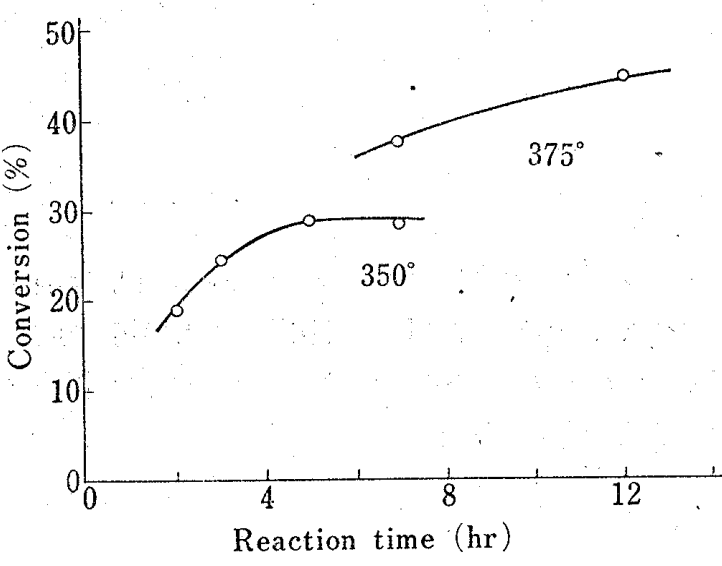

Fig. 2. Methylation of Phenol with Methanol in the Presence of Chromic Phosphate at $350^{\circ}$ and $375^{\circ}$

Phenol $(10 \mathrm{~g})$, methanol $(15 \mathrm{~g})$ and chromic phosphate $(1 \mathrm{~g})$ were used.

\section{金属の硝酸塩を触媒とするフェノール類のメチル化}

金属の硝酸塩にはフェノール類の核メチル化に活性を示する のが多い(Table II), 特飞, 硝酸鉄, 硝酸クロムはメタノール をアルキル化剂としたとき ortho 位核メチルフェノール類を選 択的に生成する。エーテル化には弱い活性しか示さなかった $\mathrm{Fe}$ の塩でも硝酸塩では核メチル化への変換率が高い。また， 反応後の系内には硝酸塩として添加した金属の酸化物が析出し ている場合がある：硝酸塩による核メチル化の理由として Fe および Cr の酸化物による ortho 位選択的核メチル化作用を すでに見い出しているので, ${ }^{3)}$ 反応の初期に和いて硝酸塩の分 解が括きて実質的には金属酸化物として核メチル化を行ってい るものと考元られる．硝酸クロムを触媒としたときの 3,5-キシ レノールに対するメチル化は Fig. 3. に示す椂にメタノールの モル比を選ぶことによって 2,3,5-トリメチルフェノールおよび 2,3,5,6-テトラメチルフェノールをそれぞれ選択性良く合成す ることができた。

\section{金属塩触媒によるメチル化の経路}

金属の塩酸塩, 硫酸塩, リン酸塩は一般にフェノールとメタノールから脱水的にアニソールを生成した. 生成 物分布から，酸触媒によるメチル化が Chart 1 に示すような逐次反応と考兄られるので、アニソールは核メチル 体生成の中間体となっている，したがって，エーテル体を選択的に合成するには適度な酸強度が要求される。金 属硫酸塩には中程度の酸強度を示すものが多く,4) 例えば，種々の金属硫酸塩を触媒としたプロピレンの水和反応 に拈いて， $\mathrm{H}_{0}=+1.5--3$ の酸強度が有効であると報告されている.5)一方，無水の金属塩化物，特に，無水塩 化覀鉛では $350^{\circ}$ でも全く選択性が認められない。また，酸性酸化物としてのシリカーアルミナ，酸化モリブデン， 酸化タングステンに招いても類似の傾向が認められ，エーテル体の転位と異性化を伴う3，ので選択率が低下する。

4）田部浩三，竹下常一，“酸塩基触媒,”産業図書, 東京, 1966, p. 202.

5) 荻野義定，触媒，4,73 (1962).

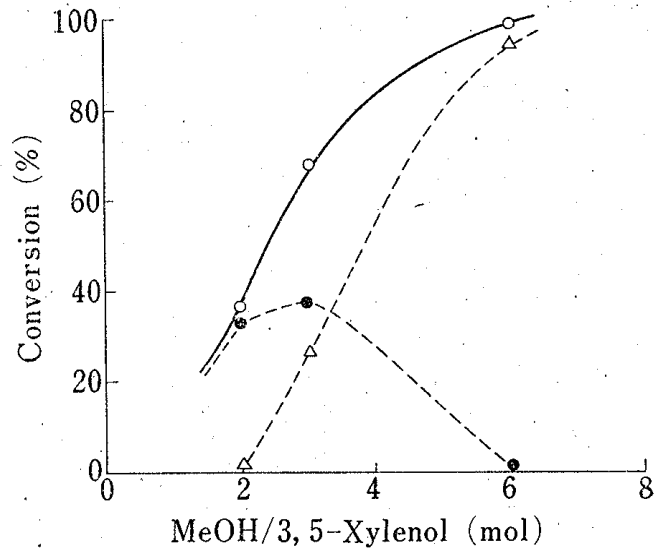

Fig. 3. Methylation of 3,5-Xylenol with Methanol in the Presence of Chromic Nitrate

The methylation was performed at $400^{\circ}$ for $3 \mathrm{hr}$.

$-8-: 2,3,5$-trimethylphenol
$-\triangle-: 2,3,5,6$-tetramethylpheno
-O-: conversion 
<smiles>COc1ccccc1C=Cc1cccc(O)c1</smiles>

Chart 1

また，アニソールからクレゾールヘの転位速度は酸性酸化物》両性金属酸化物>塩基性金属酸化物の順となり， 酸化クロムでもメチル化に比べて転位の速度が小さい.3) したがって，金属硝酸塩の分解によって生じた金属酸化 物上での ortho 位核メチル化には，エーテル体を経由する逐次的なメチル化の他に，直接核メチル化を行う経路 が存在するるのと考它られる。 